\title{
Multiplicity of Plasmodium falciparum infection following intermittent preventive treatment in infants
}

\author{
Ulrike Buchholz ${ }^{1}$, Robin Kobbe ${ }^{2}$, Ina Danquah ${ }^{1}$, Philipp Zanger ${ }^{1,3}$, Klaus Reither ${ }^{1,4}$, Harry H Abruquah ${ }^{5}$,
} Martin P Grobusch ${ }^{3,6,7}$, Peter Ziniel ${ }^{8,9}$, Jürgen May ${ }^{2}$, Frank P Mockenhaupt ${ }^{1 *}$

\begin{abstract}
Background: Intermittent preventive treatment in infants with sulphadoxine-pyrimethamine (IPTi-SP) reduces malaria morbidity by $20 \%$ to $33 \%$. Potentially, however, this intervention may compromise the acquisition of immunity, including the tolerance towards multiple infections with Plasmodium falciparum.

Methods: Plasmodium falciparum isolates were obtained from children participating in two Ghanaian IPTi-SP trials (Tamale, Afigya Sekyere) at 15 months of age, i.e., six months after they had received the second dose of IPTi-SP or placebo. By typing the polymorphic merozoite surface protein 1 (msp 1) and msp2 genes, multiplicity of infection (MOI) was assessed in 389 isolates. A total of additional 133 samples were collected in Tamale at 3, 6, 9, and 12 months of age. Comparisons of $\mathrm{MOI}$ between groups were done by non-parametric statistical tests.

Results: The number of distinguishable P. falciparum clones (MOI) ranged between one and six. Mean $\mathrm{MOI}$ in Tamale was stable at $2.13-2.17$ during the first year of life, and increased to 2.57 at age 15 months $(P=0.01)$. At no age did $\mathrm{MOI}$ differ between the IPTi-SP and placebo groups (each, $P \geq 0.5$ ). At 15 months of age, i.e., six months after the second dose, $\mathrm{MOI}$ was very similar for children who had received IPTi or placebo (means, 2.25 vs. 2.33; $P=0.55$ ) as was the proportion of polyclonal infections (69.6\% vs. $69.7 \% ; P=0.99)$. Adjusting for study site, current and prior malaria, parasite density, and season did not change this finding.

Conclusions: IPTi-SP appears to have no impact on the multiplicity of infection during infancy and thereafter. This suggests that tolerance of multiple infections, a component of protective immunity in highly endemic areas, is not affected by this intervention.
\end{abstract}

\section{Background}

Efficient and safe means of controlling falciparum malaria in endemic areas are urgently needed to reduce its intolerable high burden, particularly in young children. Reducing parasite exposure, however, may compromise the acquisition of protective immunity, as has been debated with respect to vector control and was observed following chemoprophylaxis [1-3].

Multiplicity of infection (MOI) denotes the number of distinguishable Plasmodium falciparum clones per isolate. Commonly, MOI is assessed by using the

\footnotetext{
* Correspondence: frank.mockenhaupt@charite.de

${ }^{1}$ Institute of Tropical Medicine and International Health, Charité - University Medicine, Berlin, Germany

Full list of author information is available at the end of the article
}

polymorphic regions of $P$. falciparum merozoite surface proteins 1 and 2 genes ( $m s p 1 / 2)$ as markers. In that, inter-laboratory differences exist [4], and methods displaying higher parasite diversity have been developed [5]. Irrespective of that, MOI has been considered to be subject to and to form part of the complex immune mechanisms in malaria. In children intensely exposed to antigenically diverse parasites, MOI is considered to roughly indicate the extent of acquired immunity by reflecting tolerance to multiclonal infections. These, in turn, may stimulate and maintain cross-protective immune responses [6,7]. The association between MOI and the subsequent risk of malarial disease is intricate and depends on, e.g., age and transmission intensity. At intense transmission, MOI increases in parallel to the 
acquisition of immunity and to the ability to control parasitaemia [6]. Indeed, among older children living in these areas, high MOI has repeatedly been associated with protection from subsequent clinical episodes [7-12]. In contrast, P. falciparum infections of comparatively short duration in infants preclude tolerance [13], and multiclonal infections rather increase the risk of clinical attacks [14-16]. The latter is also observed in areas of moderate transmission $[7,16,17]$.

Intermittent preventive treatment in infants (IPTi) denotes the administration of a curative dose of an antimalarial, commonly sulphadoxine-pyrimethamine (SP) at the times of routine vaccination, regardless of whether a child is parasitaemic or not. IPTi with SP (IPTi-SP) was initially tested in Tanzania also as an approach to avoid the rebound effect of increasing morbidity following chemoprophylaxis. In that initial study, IPTi-SP reduced the incidence of malaria in infancy by $59 \%$ without evidence of a rebound effect [18]. In five subsequent trials using slightly different treatment schedules, this protective efficacy ranged between $20 \%$ and 33\% [19-23]. Overall, IPTi-SP in these six trials in Tanzania, Mozambique, Ghana and Gabon had a protective efficacy against clinical malaria of $30 \%$ in the first year of life [24]. Evidence for a rebound of malaria (high density parasitaemia, severe malaria) in the second year of life was observed in two studies [19,22]. Meanwhile, IPTi has been tested at further sites and using different drugs $[25,26]$, and WHO considers IPTi for implementation in areas of moderate to high transmission and where SP resistance is not high [27].

So far, only scarce data are available on the effect of anti-malarial interventions on MOI. In Tanzania, MOI was significantly reduced among infants infected despite chemoprophylaxis and this reduction was suggested to be involved in the subsequent rebound in clinical malaria episodes [28]. RTS, S vaccination reduced MOI in Mozambique and Kenya [29,30] whereas insecticidetreated nets (ITNs) left MOI virtually unchanged in Tanzania [31]. Here, in two Ghanaian IPTi cohorts, a potential sustained impact of IPTi on multiclonal infections was examined by assessing MOI in infected children six months after they received their second dose of IPTi-SP.

\section{Methods}

Plasmodium falciparum isolates obtained from children participating in two related, randomized IPTi trials conducted in Tamale, hyperendemic northern Ghana, and in Afigya Sekyere district, holoendemic southern Ghana, were examined. The attempt of identical examinations in the IPTi trial from Lambaréné, Gabon [23], was abandoned because of scarce availability of positive samples precluding a meaningful analysis. The study protocols were reviewed and approved by the Ethics Committees, University for Development Studies, Tamale, Kwame Nkrumah University of Science and Technology, Kumasi, and International Foundation of the Albert Schweitzer Hospital, Lambaréné, and informed consent was obtained from the children's parents. Details of the site characteristics and the analysed two trials have been presented elsewhere. The trial in Tamale was performed from March 2003 through July 2005, and the one in Afigya Sekyere from January 2003 through September 2005 $[21,22]$. Briefly, while Tamale is a city of some 350,000 inhabitants but of rather rural character, the study in Afigya Sekyere comprised nine villages of 1,500 to 13,000 inhabitants. Malaria transmission is perennial with seasonal variation at both sites; entomologic data are not available for Tamale but in Afigya Sekyere, approximately 400 infective bites per person-year were observed in 2003-2005 (unpublished data). Coverage with insecticide-treated bed nets was low at $\leq 3 \%$ in both sites in 2003-2005 [21,22]. In the first year of life, the incidence of malaria has been estimated as 0.95 and 1.27 episodes per person-years at risk in Tamale and Afigya Sekyere, respectively [24]. In the two IPTi trials, 2270 children were recruited at three months of age and followed up actively in three-monthly (Tamale) or monthly (Afigya Sekyere) intervals, and passively, until 24 months of age. IPTi-SP or placebo was administered at ages 3, 9, and 15 months. Active follow-up included clinical examination, regular blood sampling, and parasitological and haematological examinations. During passive follow-up visits, i.e. when patients presented independently from regular visits, identical procedures were done as detailed elsewhere [21,22]. Episodes of malaria were treated with artesunate $(4 \mathrm{mg} / \mathrm{kg}$, double dose on first day, for five days, Tamale) or amodiaquine-artesunate $(10 / 4 \mathrm{mg} / \mathrm{kg}$ for three days, Afigya Sekyere). A sample size of $\geq 1,070$ infants in each trial was estimated to provide $80 \%$ power for detecting a $20 \%$ reduction of hazards of developing malaria in the SP group, compared with the placebo group $[21,22]$.

On the day of IPTi dose-3, i.e., six months following IPTi dose- 2 and at approximately 15 months of age, venous blood samples were collected. These were stabilized by adding an equal volume of DNA-stabilizing buffer (AS1, Qiagen, Germany), stored at $+4^{\circ} \mathrm{C}$, and DNA was extracted by commercial kits (QIAmp, Qiagen, Germany). All samples with microscopically confirmed $P$. falciparum parasitaemia were subjected to assessing MOI. For that, sequences corresponding to the allelic families of $P$. falciparum msp1 block 2 (K1, Mad20, Ro33) and of $m s p 2$ block 3 (FC27, IC) were amplified in five separate nested PCR assays [32]. These alleles are characterized by conserved regions flanked by repeat sequences of variable length. Therefore, size variation 
within the alleles can be used to discriminate different parasite clones by PCR fragment length polymorphism. Fragments were separated on $3 \% \mathrm{GTG}^{\oplus}$-agarose gels (Biozym, Germany) and analysed using GeneSnap software (SynGene, UK). In case of negative or inconclusive PCR results, assays were repeated maximally twice. MOI was calculated as the highest number of fragments for either $m s p 1$ or $m s p 2$. Of a total of 348 microscopically positive samples collected at 15 months of age, MOI could be assessed in 277 (79.6\%). For the Tamale trial, all samples collected at 15 months of age were examined by Plasmodium-specific nested PCR assays [33] and msp1/2 genotyping was extended to additional 142 samples identified to have submicroscopic parasitaemia of which 112 yielded a result for MOI (typing efficiency, 78.9\%). Also, for the Tamale cohort, a random sample of microscopically positive samples (if available, each 25 for placebo and IPTi-SP groups) collected at 3, 6, 9, and 12 months of age was genotyped to illustrate the development of MOI with age (typing efficiency, $72.2 \%$ ). For all samples, processing and DNA extraction were performed in a standardized manner, and all samples were typed at the Institute of Tropical Medicine in Berlin, Germany.

Malaria was defined by the presence of microscopically visible parasitaemia plus fever (axillary temperature, $\geq 37.5^{\circ} \mathrm{C}$, or, Afigya Sekyere, $\geq 38.0,<12$ months, rectally; $\geq 12$ months, tympanically) or fever during the preceding 48 hours reported by mothers without being asked. For incidence estimates, children were regarded as not being at risk for 21 days following an episode of malaria and person-time-at-risk was reduced accordingly. Polyclonal infections had a MOI of $>1$. Rainy season (> 10 days or $>90 \mathrm{~mm}$ of precipitation/month) was defined as before [5,22].

Continuous parameters were compared between groups by the non-parametric Mann-Whitney U-test or Kruskal-Wallis test. These tests were also applied to compare MOI between groups but results are primarily presented as arithmetic means since this measure of average more selectively displays (the direction of) differences than medians, which are also shown, nevertheless. Proportions of polyclonal infections were analysed by $\chi^{2}$ tests. In multivariate analysis, known or potential confounders of the proportion of polyclonal infections and MOI were adjusted for by including these in logistic regression models and by applying non-parametric multiple ordinal regression, respectively.

\section{Results}

The characteristics of the 1086 children at 15 months of age from Tamale and their 964 peers from Afigya Sekyere are shown in Table 1. As compared to children from Tamale, their peers from Afigya Sekyere showed more microscopically determined parasitaemia, more frequently had a current episode of malaria but less frequently were febrile or anaemic. Also, more children from Afigya Sekyere than from Tamale had had malaria until 15 months of age, and the number of previous episodes was higher. Most children in Tamale had their scheduled visit at 15 months of age during the rainy season, but only roughly half in Afigya Sekyere (Table 1).

In Tamale and Afigya Sekyere, IPTi-SP at ages 3 and 9 months had achieved reductions in the incidence of malaria until 15 months of age of $24 \%$ (13-33\%) and $20 \%$ (95\%CI, $12-28 \%$ ), respectively, largely due to incidence reductions during the first month following each treatment [21,22,24]. At 15 months of age, no impact of previous IPTi-SP on malariometric parameters was discernible: children who had received IPTi-SP or placebo showed similar prevalences of asymptomatic parasitaemia $(16.9 \%(172 / 1015)$ vs. $17.4 \%(176 / 1013), P=0.80)$ and malaria $(9.6 \%(97 / 1015)$ vs. $8.9 \%(90 / 1013), P=$ $0.60)$. Also, GMPDs $(95 \% \mathrm{CI})$ were alike (1622 (11752238) vs. $1791(1318-2432) / \mu \mathrm{L}, P=0.66)$.

The development of MOI with age in Tamale is shown in Figure 1. Overall, MOI was stable at a mean of $2.13-2.17$ (medians, each 2) during the first year of life $(P=1.0)$, and increased to 2.57 (median, 2; range $1-5)$ at age 15 months $(P=0.01)$. At no age, did MOI differ between IPTi-SP and placebo groups $(P \geq 0.5)$. Lacking impact of IPTi-SP on MOI was confirmed when adjusting for parasite density and age by multiple ordinal regression $(P=0.32$; Figure 1$)$.

At 15 months of age, a total of 277 samples with microscopically visible parasitaemia were successfully genotyped, comprising 163 (58.8\%) samples of malaria cases. The distribution of MOI in these 277 samples is shown in Figure 2. Further 112 specimens of submicroscopic infections were available from Tamale. Irrespective of study site, MOI (mean, 2.29; median, 2; range, 16 ) and the proportion of polyclonal P. falciparum infections $(69.7 \%)$ were similar among former IPTi-SP and placebo recipients. This was true for both microscopically identified and submicroscopic infections (Table 2).

Known factors influencing multiplicity and potential confounders were tested (Table 3): MOI (and polyclonal infections) in microscopically positive samples were increased in children with current malaria, tended to be higher in Tamale than in Afigya Sekyere, and increased with parasite density (Table 3). Prior occurrence of malaria was not associated with MOI itself but, at borderline significance, with less polyclonal infections. A lowered multiplicity of $P$. falciparum in the rainy season was observed only in multivariate analysis. Adjusting for these factors, the finding that previous IPTi-SP did not influence the multiplicity of $P$. falciparum infection was confirmed (Table 3). 
Table 1 Characteristics of 2050 Ghanaian children at 15 months of age, i.e. six month after the third dose of IPTi-SP

\begin{tabular}{|c|c|c|c|}
\hline Parameter & Tamale & Afigya Sekyere & $P$ \\
\hline No. & 1086 & 964 & \\
\hline Proportion girls (\%) & 50.2 & 49.3 & 0.68 \\
\hline Examination for present study (15 months of age) in rainy season (\%) & 89.6 & 49.3 & $<0.0001$ \\
\hline SP group : placebo group & $542: 544$ & $485: 479$ & 0.86 \\
\hline \multicolumn{4}{|l|}{ Current $P$. falciparum infection } \\
\hline by microscopy $(\% ; n / n)$ & $11.0(119 / 1084)$ & $24.3(229 / 944)$ & $<0.0001$ \\
\hline GMPD (parasites/ $\mu \mathrm{L}, 95 \% \mathrm{Cl})$ & $2312(1599-3344)$ & $1455(1105-1917)$ & 0.03 \\
\hline by PCR (\%) & $23.6(248 / 1049)$ & n.a. & - \\
\hline Current malaria episode $(\%, \mathrm{n} / \mathrm{n})$ & $7.4(80 / 1084)$ & $11.3(107 / 944)$ & 0.002 \\
\hline Febrile $(\%, n / n)$ & $12.8(138 / 1082)$ & $6.1(59 / 964)$ & $<0.0001$ \\
\hline History of fever within $48 \mathrm{~h}(\%, \mathrm{n} / \mathrm{n})$ & $31.7(344 / 1086)$ & $31.8(307 / 964)$ & 0.93 \\
\hline Haemoglobin (g/dL; mean, range) & $8.91(4.7-12.7)$ & $9.90(2.0-15.0)$ & $<0.0001$ \\
\hline Proportion anaemic $(\mathrm{Hb}<11 \mathrm{~g} / \mathrm{dL} ; \%, \mathrm{n} / \mathrm{n})$ & $94.0(1019 / 1084)$ & $74.4(715 / 961)$ & $<0.0001$ \\
\hline Proportion severely anaemic $(\mathrm{Hb}<7 \mathrm{~g} / \mathrm{dL} ; \%, \mathrm{n} / \mathrm{n})$ & $8.0(87 / 1084)$ & $4.9(47 / 961)$ & 0.004 \\
\hline Proportion with prior episode(s) of malaria $(\%, \mathrm{n} / \mathrm{n})$ & $47.4(515 / 1086)$ & $57.6(555 / 964)$ & $<0.0001$ \\
\hline No. of previous malaria episodes (mean, range) & $0.67(0-5)$ & $1.23(0-7)$ & $<0.0001$ \\
\hline
\end{tabular}

GMPD, geometric mean parasite density; $\mathrm{Hb}$, haemoglobin; n.a., not available

In the Tamale cohort, submicroscopic infections showed a lesser multiplicity than those microscopically visible (mean MOI, 2.02 vs. 2.57; medians (range), each $2(1-5) ; P=0.0006)$. Submicroscopic infections were arbitrarily set as 1 parasite/ $\mu \mathrm{L}$ and included into a separate multivariate analysis as above for the Tamale cohort. Again, no significant impact of IPTI-SP on MOI (regression coefficient, -0.15; standard error, 0.36; $P=$ 0.67 ) or on polyclonal infections (adjusted OR, 1.03; $95 \%$ CI, 0.56-1.87, $P=0.93$ ) was discernible.

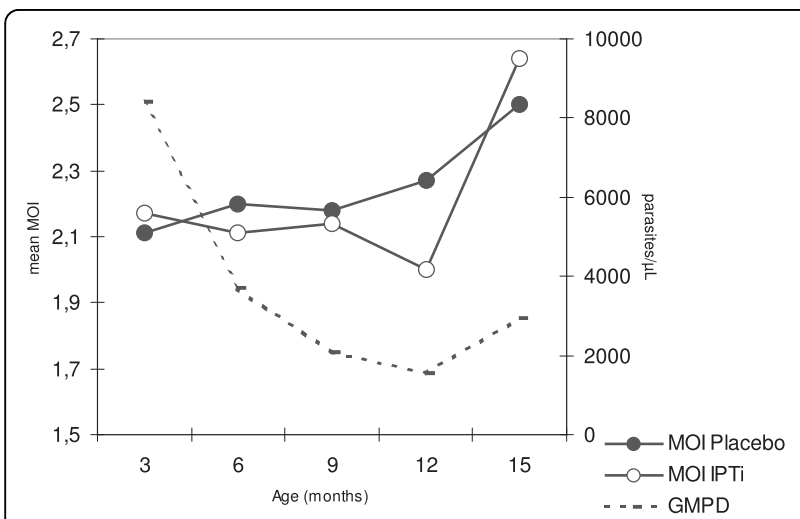

Figure 1 Multiplicity of infection and geometric mean parasite density according to age. Group sizes at ages 3, 6, 9, 12, 15 months: 15, 38, 44, 36, 104. Parasite density declines until 12 months of age and slightly increases thereafter $(P=0.08)$. IPTi had no effect on parasite density $(P=0.57)$, at no time $(P>0.4)$. In multiple, non-parametric ordinal regression analysis, IPTi had no effect on $\mathrm{MOI}$ in these children (regression coefficient, -0.33 ; standard error (SE), 0.33; $P=0.32$; age (months), 0.06, SE, 0.06; $P=0.30 ; \log 10$ parasite density, $0.78, \mathrm{SE}, 0.19 ; P<0.0001)$.
Between months 16 and 24 of follow-up of the Tamale cohort, 12 excess cases of severe malaria were observed in the previous IPTi group [22]. For the six of these 12 children for whom genotyping data were available at 15 months of age, MOI did not differ from the remaining 100 children in the IPTi group (means, 2.00 vs. 2.23; medians (range), $2(1-5)$ vs. $2(1-3) ; P=0.82)$.

\section{Discussion}

In holoendemic Tanzania, continuous chemoprophylaxis in infancy reduced the multiplicity of infection with $P$. falciparum, and the rebound of malaria following that intervention has been attributed to this reduction [28]. In the present analysis of two IPTi-SP cohorts from hyper- and holoendemic Ghana, no evidence was found that this intervention has a sustainable effect on multiplicity. This finding supports the principle idea of IPTi, i.e. a basically chemoprophylactic intervention of limited duration $[21,22,24,34]$ allowing for sufficient exposure to develop and maintain immunity. In consequence also, because IPTi-SP did not affect multiplicity which has been linked to prospective risks of malaria [7-17] this study does not support the attribution of potential rebound effects to interference with MOI. In particular, in the Tamale cohort, rebound events in the former IPTi-SP recipients were not associated with MOI at 15 months. Admittedly, however, only few samples were available for analysis, and most children with later severe malaria were not infected at that time.

The present study analysed multiplicity only, i.e. one actor in the network of diverse immune mechanisms. The importance of this factor is furthermore varying with age and endemicity [7-17]. Also, the single 


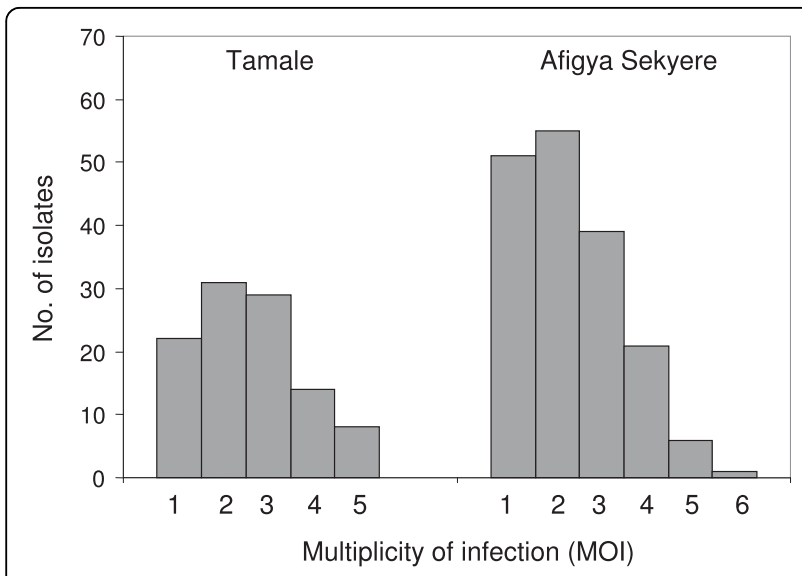

Figure 2 Distribution of MOI in Tamale and Afigya Sekyere.

assessment of MOI at 15 month of age may provide only a still image of an actually dynamic parasite composition [35]. Data were derived exclusively from infected children, i.e., the minority of individuals under study. Typing efficiency was at the lower range of previously reported results [4]. Thus, a proportion of children who were infected, presumably at very low parasite densities, could not be included into the analysis. The risk of malaria at a given time is determined by a multitude of factors including among others, host heterogeneity and temporal variation in exposure, genetics, socio-economic status, and treatment-seeking behaviour $[36,37]$ which, however, due to randomization should be evenly distributed between the placebo and IPTi groups. Thus, as one limitation of the present study, the results are valid only for those children harbouring parasites on examination, and the influence of other factors on malaria and malarial immunity may outweigh the one of multiplicity of infection.

The present data accord with previous findings from highly endemic areas $[13,14]$ in that MOI was basically stable throughout the first year of life and increased only at its end. Paralleled by the increasing ability to control parasitaemia (Figure 1) this may indicate a change of the predominant type of host response at this age. While in infancy infections are rather short-lived [13] and fever and pro-inflammatory responses are the main defence armamentarium [38], the development of tolerance to the establishment and persistence of (lowgrade) parasitaemia, i.e. premunition, is considered a prerequisite for clinical immunity [6]. However, it should be noted MOI is also interpreted alternatively, namely as a parameter of (recent) accumulation of infections, higher exposure, and possibly increased malaria incidence rather than a proxy parameter for premunition $[16,35]$. Obviously, MOI is a highly complex parameter and subject to various inter-related influences. Of note, the temporal dynamics of $P$. falciparum infection also affect the assessment of parasite populations, and single assessments may provide only a limited impression of the overall parasite composition in a host [35]. In the present study, MOI increased with parasite density likely reflecting known threshold effects in the detection of individual parasite clones [14,16,35]. The observed increased multiplicity in clinical episodes of malaria accords with some previous reports $[14,39,40]$ but contrasts with others $[41,42]$. Considering young age and endemicity, the finding of the present study that MOI is increased in malaria might result from the recent acquisition of novel parasite clones (as reflected by high MOI) which has been reported to increase the probability of simultaneous clinical episodes [13,39]. Unexpectedly, MOI was lower in the rainy than in the dry season. Despite possible distortion of results by delayed onset of increased transmission, this contrasts with previous studies $[32,43,44]$ but is in line with a study among Ghanaian infants in whom the variability of circulating allelic populations was higher in the dry season [5]. Although heterogeneity of malaria transmission, i.e. pockets of high transmission during the dry season, might be involved in a comparatively high MOI among children infected in the dry season, the actual reasons for this are, however, obscure. Prior malaria episodes rather reduced the odds of current multiclonal infection. However, the proportion of polyclonal infections did not differ between children with no previous

Table 2 Multiplicity of infection and proportion of polyclonal infections according to previous IPTi with SP

\begin{tabular}{|c|c|c|c|c|c|c|c|}
\hline \multirow[t]{2}{*}{ Stratum } & \multirow{2}{*}{$\begin{array}{c}\text { No. } \\
\text { IPTI : placebo }\end{array}$} & \multicolumn{2}{|c|}{ mean MOI (median, range) } & \multirow[t]{2}{*}{$P$} & \multicolumn{2}{|c|}{ Proportion of polyclonal infections (\%) } & \multirow[t]{2}{*}{$P$} \\
\hline & & Previous IPTi & Previous Placebo & & Previous IPTi & Previous Placebo & \\
\hline All & $191: 198$ & $2.25(2,1-5)$ & $2.33(2,1-6)$ & 0.55 & 69.6 & 69.7 & 0.99 \\
\hline All microscopically positive & $135: 142$ & $2.42(2,1-5)$ & $2.38(2,1-6)$ & 0.78 & 74.8 & 72.5 & 0.67 \\
\hline Afigya Sekyere & $85: 88$ & $2.29(2,1-5)$ & $2.31(2,1-6)$ & 0.92 & 69.4 & 71.6 & 0.75 \\
\hline Tamale, all & $106: 110$ & $2.22(2,1-5)$ & $2.35(2,1-5)$ & 0.49 & 69.8 & 68.2 & 0.80 \\
\hline Tamale, microscopically positive & $50: 54$ & $2.64(2.5,1-5)$ & $2.50(2,1-5)$ & 0.59 & 84.0 & 74.1 & 0.22 \\
\hline Tamale, submicroscopic & $56: 56$ & $1.84(2,1-5)$ & $2.20(2,1-5)$ & 0.17 & 57.1 & 62.5 & 0.56 \\
\hline
\end{tabular}

$P$, comparisons by Mann-Whitney $\mathrm{U}$ test or $\chi^{2}$ test 
Table 3 Univariate and multivariate associations with microscopically visible, polyclonal $P$. falciparum infections

\begin{tabular}{|c|c|c|c|c|c|c|c|c|c|c|c|}
\hline \multirow[t]{2}{*}{ Parameter } & \multirow[t]{2}{*}{ No. } & \multirow[t]{2}{*}{$\begin{array}{l}\text { Mean MOI (median, } \\
\text { range) }\end{array}$} & \multirow[t]{2}{*}{$P$} & \multicolumn{3}{|c|}{$\begin{array}{l}\text { Multivariate } \\
\text { analysis }^{\mathrm{a}}\end{array}$} & \multirow[t]{2}{*}{$\begin{array}{l}\text { Polyclonal infections } \\
\text { (\%) }\end{array}$} & \multirow[t]{2}{*}{ OR $(95 \% \mathrm{Cl})$} & \multirow[t]{2}{*}{$P$} & \multicolumn{2}{|c|}{$\begin{array}{c}\text { Multivariate } \\
\text { analysis }^{\mathbf{b}}\end{array}$} \\
\hline & & & & b & SE & $P$ & & & & aOR $(95 \% \mathrm{Cl})$ & $P$ \\
\hline \multicolumn{12}{|l|}{ Previous IPTi-SP } \\
\hline No & 142 & $2.38(2,1-6)$ & & & & & 72.5 & 1 & & 1 & \\
\hline Yes & 135 & $2.42(2,1-5)$ & 0.78 & -0.05 & 0.22 & 0.82 & 74.8 & $\begin{array}{l}1.12(0.64- \\
1.99)\end{array}$ & 0.67 & $0.93(0.52-1.64)$ & 0.79 \\
\hline \multicolumn{12}{|l|}{ Cohort } \\
\hline Tamale & 104 & $2.57(2,1-5)$ & & & & & 78.8 & 1 & & 1 & \\
\hline $\begin{array}{l}\text { Afigya } \\
\text { Sekyere }\end{array}$ & 173 & $2.30(2,1-6)$ & 0.07 & -0.67 & 0.26 & 0.01 & 70.5 & $\begin{array}{c}0.64(0.35- \\
1.18)\end{array}$ & 0.13 & $0.53(0.28-1.03)$ & 0.06 \\
\hline \multicolumn{12}{|c|}{ Current malaria episode } \\
\hline No & 114 & $2.21(2,1-6)$ & & & & & 64.0 & 1 & & 1 & \\
\hline Yes & 163 & $2.53(2,1-5)$ & 0.01 & 0.55 & 0.24 & 0.02 & 80.4 & $\begin{array}{l}2.30(1.29- \\
4.11)\end{array}$ & 0.002 & $2.35(1.27-4.32)$ & 0.006 \\
\hline \multicolumn{12}{|c|}{ Parasite density $(/ \mu \mathrm{L})$} \\
\hline $\log 10$ & 277 & n.a. & 0.049 & 0.24 & 0.13 & 0.07 & n.a. & $\begin{array}{l}1.48(1.08- \\
2.03)\end{array}$ & 0.01 & $1.38(0.99-1.94)$ & 0.06 \\
\hline \multicolumn{12}{|c|}{ Prior malaria episodes } \\
\hline None & 72 & $2.50(2,1-5)$ & & & & & 81.9 & 1 & & 1 & \\
\hline Any & 205 & $2.37(2,1-6)$ & 0.30 & -0.19 & 0.26 & 0.46 & 70.7 & $\begin{array}{l}0.53(0.26- \\
1.09)\end{array}$ & 0.06 & $0.51 \underset{d}{(0.25-1.05)^{c}}$ & 0.07 \\
\hline \multicolumn{12}{|l|}{ Season } \\
\hline Dry season & 92 & $2.49(2,1-5)$ & & & & & 79.3 & 1 & & 1 & \\
\hline $\begin{array}{l}\text { Rainy } \\
\text { season }\end{array}$ & 185 & $2.36(2,1-6)$ & 0.32 & -0.77 & 0.27 & 0.004 & 70.8 & $\begin{array}{l}1.58(0.84- \\
3.01)\end{array}$ & 0.13 & $0.36(0.18-0.72)$ & 0.004 \\
\hline
\end{tabular}

${ }^{a}$, multivariate results are derived from non-parametric ordinal regression analysis including all listed parameters. ${ }^{b}$, adjusted odds ratios (aORs) are derived from logistic regression models including all other listed parameters; SE, standard error; OR, odds ratio; $95 \% \mathrm{Cl}, 95 \%$ confidence interval; n.a., not applicable; ${ }^{\text {, }}$ exchanging with number of previous malaria episodes (0-7): aOR, $0.98,95 \% \mathrm{Cl}, 0.81-1.19 ; P=0.84{ }^{\mathrm{d}}$, The proportion of polyclonal infections according to arbitrarily set time periods from last previous episode was: $<8$ weeks $(n=65), 76.9 \%$; 8-16 weeks $(n=62), 72.6 \%$; $>16$ weeks $(n=78), 64.1 \%$. Exchanging this graded parameter with prior episodes per se yielded respective aORs (95\%Cls) of $0.73(0.30-1.78), 0.72(0.29-1.76)$, and $0.32(0.14-0.73)$.

or recent malaria, and among those with prior episodes, there was a trend for less polyclonal infections the longer the last episode dated back (Table 3). Thus, considering that short-lived immune mechanisms evoked by an infection and controlling (rather than eliminating) multiple infections form the backbone of the concept of premunition [6], this finding may reflect a temporal decline in the ability to tolerate infection following an episode. Lastly, multiplicity tended to be higher in Tamale than in Afigya Sekyere although the opposite was expected $[7,16,17,43]$. Possibly, a de facto higher incidence of malaria has been missed in Tamale due to the comparatively broader mesh of active follow-up. Also, the use of artesunate for treatment there as compared to long-acting artesunate-amodiaquine in Afigya Sekyere might be involved in a more intense exposure.

\section{Conclusions}

IPTI-SP did not influence the multiplicity of P. falciparum up to the age of 15 months, although it reduced the incidence of malaria in the two trials by $24 \%$ and $20 \%$. This effect on malaria could largely be attributed to a prophylactic effect of approximately one month duration following treatment $[21,22,24]$. This resembles the situation with ITNs, i.e., morbidity reduction and absent effect on multiplicity [31] suggesting that imperfect or short-lived interventions allow for sufficient exposure. Vice versa, the reduction of MOI following RTS, S vaccination $[29,30]$ might reflect its long-lasting activity. IPTi-SP is debated controversially $[24,45,46]$, reasons including the absence of effect in areas of high SP resistance [25], potential contributions to the emergence of drug resistance [47], and clues for rebound effects $[19,21,22]$. As for the latter, no evidence was found suggesting that interference with multiplicity of infection could be involved as has been proposed for chemoprophylaxis [28]. The present study also highlights that MOI is influenced by various factors which need to be taken into account when interpreting the respective effects of interventions. The impact of IPTi on multiplicity of infection and the development of immunity using alternative, long-acting drugs which likely will replace SP in the future [25] needs to be defined. 


\section{Acknowledgements}

This work was supported by the German Research Foundation (DFG, grant Mo 852/2-1), and forms part of the doctoral thesis of UB. The IPTi cohorts in Tamale, Afigya Sekyere and Lambaréné were funded by the German Ministry of Education and Research (grant 01KA0202) and the German Academic Exchange Service (DAAD). We thank all participants and their families for participating in the study, the members of the Northern Region Malaria Project (NORMAP) and the Kumasi Centre for Collaborative Research in Tropical Medicine (KCCR), and the Ghana Health Service.

\section{Author details}

${ }^{1}$ Institute of Tropical Medicine and International Health, Charité - University Medicine, Berlin, Germany. ${ }^{2}$ Infectious Disease Epidemiology Group, Bernhard Nocht Institute for Tropical Medicine, Hamburg, Germany. ${ }^{3}$ Institute of Tropical Medicine, University of Tuebingen, Tuebingen, Germany. ${ }^{4}$ Swiss Tropical and Public Health Institute, Basel, Switzerland. ${ }^{5}$ Division of Microbiology and Infectious Diseases, University Hospital, Kwame Nkrumah University of Science and Technology, Kumasi, Ghana. ${ }^{6}$ Medical Research Unit, Hôpital Albert Schweitzer, Lambaréné, Gabon. Department of Infectious Diseases, Tropical Medicine, HIV/AIDS, Amsterdam Medical Center, University of Amsterdam, The Netherlands. ${ }^{8}$ Northern Region Malaria Project, Tamale, Ghana. ${ }^{9}$ Dept. of Immunology \& Microbiology, Rush University, Chicago, USA.

\section{Authors' contributions}

FPM, JM, and MPG designed the study. PZa, KR, SA, RK, HHA, and Pzi were responsible for patient recruitment, and clinical and parasitological examinations. UB did the genotyping, and ID and FPM the statistical analyses. UB, ID and FPM wrote the paper with major contributions of the other authors. All authors read and approved the final manuscript.

\section{Competing interests}

The authors declare that they have no competing interests.

Received: 11 June 2010 Accepted: 26 August 2010

Published: 26 August 2010

\section{References}

1. Snow RW, Omumbo JA, Lowe B, Molyneux CS, Obiero JO, Palmer A, Weber MW, Pinder M, Nahlen B, Obonyo C, Newbold C, Gupta S, Marsh K: Relation between severe malaria morbidity in children and level of Plasmodium falciparum transmission in Africa. Lancet 1997, 349:1650-1654.

2. Menendez C, Kahigwa E, Hirt R, Vounatsou P, Aponte JJ, Font F, Acosta CJ, Schellenberg DM, Galindo CM, Kimario J, Urassa H, Brabin B, Smith TA, Kitua AY, Tanner M, Alonso PL: Randomised placebo-controlled trial of iron supplementation and malaria chemoprophylaxis for prevention of severe anaemia and malaria in Tanzanian infants. Lancet 1997, 350:844-850.

3. Greenwood BM, David PH, Otoo-Forbes LN, Allen SJ, Alonso PL, Armstrong Schellenberg JR, Byass P, Hurwitz M, Menon A, Snow RW: Mortality and morbidity from malaria after stopping malaria chemoprophylaxis. Trans $R$ Soc Trop Med Hyg 1995, 89:629-633.

4. Färnert A, Arez AP, Babiker HA, Beck HP, Benito A, Björkman A, Bruce MC, Conway DJ, Day KP, Henning L, Mercereau-Puijalon O, RanfordCartwright LC, Rubio JM, Snounou G, Walliker D, Zwetyenga J, do Rosario VE: Genotyping of Plasmodium falciparum infections by PCR: a comparative multicentre study. Trans R Soc Trop Med Hyg 2001, 95:225-232.

5. Kobbe R, Neuhoff R, Marks F, Adjei S, Langefeld I, von Reden C, Adjei O, Meyer CG, May J: Seasonal variation and high multiplicity of first Plasmodium falciparum infections in children from a holoendemic area in Ghana, West Africa. Trop Med Int Health 2006, 11:613-619.

6. Smith T, Felger I, Tanner M, Beck HP: Premunition in Plasmodium falciparum infection: insights from the epidemiology of multiple infections. Trans R Soc Trop Med Hyg 1999, 93(Suppl 1):59-64.

7. Färnert A, Williams TN, Mwangi TW, Ehlin A, Fegan G, Macharia A, Lowe BS, Montgomery SM, Marsh K: Transmission-dependent tolerance to multiclonal Plasmodium falciparum infection. J Infect Dis 2009, 200:1166-1175.

8. al-Yaman F, Genton B, Reeder JC, Anders RF, Smith T, Alpers MP: Reduced risk of clinical malaria in children infected with multiple clones of
Plasmodium falciparum in a highly endemic area: a prospective community study. Trans R Soc Trop Med Hyg 1997, 91:602-605.

9. Beck HP, Felger I, Huber W, Steiger S, Smith T, Weiss N, Alonso P, Tanner M: Analysis of multiple Plasmodium falciparum infections in Tanzanian children during the phase III trial of the malaria vaccine SPf66. I Infect Dis 1997, 175:921-926.

10. Färnert A, Rooth I, Snounou G, Björkman A: Complexity of Plasmodium falciparum infections is consistent over time and protects against clinical disease in Tanzanian children. J Infect Dis 1999, 179:989-995.

11. Müller DA, Charlwood JD, Felger I, Ferreira C, do Rosario V, Smith T: Prospective risk of morbidity in relation to multiplicity of infection with Plasmodium falciparum in São Tomé. Acta Trop 2001, 78:155-162.

12. Bereczky S, Liljander A, Rooth I, Faraja L, Granath F, Montgomery SM, Färnert A: Multiclonal asymptomatic Plasmodium falciparum infections predict a reduced risk of malaria disease in a Tanzanian population. Microbes Infect 2007, 9:103-110.

13. Smith T, Felger I, Kitua A, Tanner M, Beck HP: Dynamics of multiple Plasmodium falciparum infections in infants in a highly endemic area of Tanzania. Trans R Soc Trop Med Hyg 1999, 93(Suppl 1):35-39.

14. Felger I, Smith T, Edoh D, Kitua A, Alonso P, Tanner M, Beck HP: Multiple Plasmodium falciparum infections in Tanzanian infants. Trans $R$ Soc Trop Med Hyg 1999, 93(Suppl 1):29-34.

15. Henning L, Schellenberg D, Smith T, Henning D, Alonso P, Tanner M, Mshinda H, Beck HP, Felger I: A prospective study of Plasmodium falciparum multiplicity of infection and morbidity in Tanzanian children. Trans R Soc Trop Med Hyg 2004, 98:687-694.

16. Mayor A, Saute F, Aponte JJ, Almeda J, Gómez-Olivé FX, Dgedge M, Alonso PL: Plasmodium falciparum multiple infections in Mozambique, its relation to other malariological indices and to prospective risk of malaria morbidity. Trop Med Int Health 2003, 8:3-11.

17. Roper C, Richardson W, Elhassan IM, Giha H, Hviid L, Satti GM, Theander TG, Arnot DE: Seasonal changes in the Plasmodium falciparum population in individuals and their relationship to clinical malaria: a longitudinal study in a Sudanese village. Parasitology 1998, 116:501-510.

18. Schellenberg D, Menendez C, Kahigwa E, Aponte J, Vidal J, Tanner M, Mshinda $\mathrm{H}$, Alonso P: Intermittent treatment for malaria and anaemia control at time of routine vaccinations in Tanzanian infants: a randomised, placebo-controlled trial. Lancet 2001, 357:1471-1477.

19. Chandramohan D, Owusu-Agyei S, Carneiro I, Awine T, Amponsa-Achiano K, Mensah N, Jaffar S, Baiden R, Hodgson A, Binka F, Greenwood B: Cluster randomised trial of intermittent preventive treatment for malaria in infants in area of high, seasonal transmission in Ghana. BMJ 2005, 331:727-733.

20. Macete E, Aide P, Aponte JJ, Sanz S, Mandomando I, Espasa M, Sigauque B, Dobaño C, Mabunda S, DgeDge M, Alonso P, Menendez C: Intermittent preventive treatment for malaria control administered at the time of routine vaccinations in Mozambican infants: a randomized, placebocontrolled trial. J Infect Dis 2006, 194:276-285.

21. Kobbe R, Kreuzberg C, Adjei S, Thompson B, Langefeld I, Thompson PA, Abruquah HH, Kreuels B, Ayim M, Busch W, Marks F, Amoah K, Opoku E, Meyer CG, Adjei O, May J: A randomized controlled trial of extended intermittent preventive antimalarial treatment in infants. Clin Infect Dis 2007, 45:16-25.

22. Mockenhaupt FP, Reither $K$, Zanger P, Roepcke F, Danquah I, Saad E, Ziniel P, Dzisi SY, Frempong M, Agana-Nsiire P, Amoo-Sakyi F, Otchwemah R, Cramer JP, Anemana SD, Dietz E, Bienzle U: Intermittent preventive treatment in infants as a means of malaria control: a randomized, double-blind, placebo-controlled trial in northern Ghana. Antimicrob Agents Chemother 2007, 51:3273-3281.

23. Grobusch MP, Lell B, Schwarz NG, Gabor J, Dornemann J, Potschke M, Oyakhirome S, Kiessling GC, Necek M, Langin MU, Klein Klouwenberg P, Klopfer A, Naumann B, Altun H, Agnandji ST, Goesch J, Decker M, Salazar CL, Supan C, Kombila DU, Borchert L, Koster KB, Pongratz P, Adegnika AA, Glasenapp I, Issifou S, Kremsner PG: Intermittent preventive treatment against malaria in infants in Gabon-a randomized, doubleblind, placebo-controlled trial. J Infect Dis 2007, 196:1595-1602.

24. Aponte JJ, Schellenberg D, Egan A, Breckenridge A, Carneiro I, Critchley J, Danquah I, Dodoo A, Kobbe R, Lell B, May J, Premji Z, Sanz S, Sevene E, Soulaymani-Becheikh R, Winstanley P, Adjei S, Anemana S, Chandramohan D, Issifou S, Mockenhaupt F, Owusu-Agyei S, Greenwood B, Grobusch MP, Kremsner PG, Macete E, Mshinda H, Newman RD, Slutsker L, 
Tanner M, Alonso P, Menendez C: Efficacy and safety of intermittent preventive treatment with sulfadoxine-pyrimethamine for malaria in African infants: a pooled analysis of six randomised, placebo-controlled trials. Lancet 2009, 374:1533-1542.

25. Gosling RD, Gesase S, Mosha JF, Carneiro I, Hashim R, Lemnge M, Mosha FW, Greenwood B, Chandramohan D: Protective efficacy and safety of three antimalarial regimens for intermittent preventive treatment for malaria in infants: a randomised, double-blind, placebo-controlled trial. Lancet 2009, 374:1521-1532.

26. Odhiambo FO, Hamel MJ, Williamson J, Lindblade K, ter Kuile FO, Peterson E, Otieno P, Kariuki S, Vulule J, Slutsker L, Newman RD: Intermittent preventive treatment in infants for the prevention of malaria in rural Western kenya: a randomized, double-blind placebocontrolled trial. PLoS One 2010, 5:e10016.

27. WHO: WHO Policy recommendation on Intermittent Preventive Treatment during infancy with sulphadoxine-pyrimethamine (SP-IPTi) for Plasmodium falciparum malaria control in Africa (March 2010). World Health Organisation, Geneva, Switzerland. [http://www.who.int/malaria/ news/WHO_policy_recommendation_IPTi_032010.pdf].

28. Beck HP, Felger I, Vounatsou P, Hirt R, Tanner M, Alonso P, Menendez C: Effect of iron supplementation and malaria prophylaxis in infants on Plasmodium falciparum genotypes and multiplicity of infection. Trans $R$ Soc Trop Med Hyg 1999, 93(Suppl 1):41-45.

29. Enosse S, Dobaño C, Quelhas D, Aponte JJ, Lievens M, Leach A, Sacarlal J, Greenwood B, Milman J, Dubovsky F, Cohen J, Thompson R, Ballou WR, Alonso PL, Conway DJ, Sutherland CJ: RTS, S/AS02A malaria vaccine does not induce parasite CSP T cell epitope selection and reduces multiplicity of infection. PLoS Clin Trials 2006, 1:e5.

30. Waitumbi JN, Anyona SB, Hunja CW, Kifude CM, Polhemus ME, Walsh DS, Ockenhouse CF, Heppner DG, Leach A, Lievens M, Ballou WR, Cohen JD, Sutherland CJ: Impact of RTS, S/AS02(A) and RTS, S/AS01(B) on genotypes of $P$. falciparum in adults participating in a malaria vaccine clinical trial. PLoS One 2009, 4:e7849.

31. Fraser-Hurt N, Felger I, Edoh D, Steiger S, Mashaka M, Masanja H, Smith T, Mbena F, Beck HP: Effect of insecticide-treated bed nets on haemoglobin values, prevalence and multiplicity of infection with Plasmodium falciparum in a randomized controlled trial in Tanzania. Trans $R$ Soc Trop Med Hyg 1999, 93(Suppl 1):47-51.

32. Snounou G, Zhu X, Siripoon N, Jarra W, Thaithong S, Brown KN Viriyakosol S: Biased distribution of $m s p 1$ and $m s p 2$ allelic variants in Plasmodium falciparum populations in Thailand. Trans $R$ Soc Trop Med Hyg 1999, 93:369-374.

33. Snounou G, Viriyakosol S, Jarra W, Thaithong S, Brown KN: Identification of the four human malaria parasite species in field samples by the polymerase chain reaction and detection of a high prevalence of mixed infections. Mol Biochem Parasitol 1993, 58:283-292.

34. Cairns M, Carneiro I, Milligan P, Owusu-Agyei S, Awine T, Gosling R, Greenwood B, Chandramohan D: Duration of protection against malaria and anaemia provided by intermittent preventive treatment in infants in Navrongo, Ghana. PLoS One 2008, 3:e2227.

35. Färnert A: Plasmodium falciparum population dynamics: only snapshots in time? Trends Parasitol 2008, 24:340-344.

36. Mackinnon MJ, Mwangi TW, Snow RW, Marsh K, Williams TN: Heritability of malaria in Africa. PLoS Med 2005, 2:e340.

37. Clark TD, Greenhouse B, Njama-Meya D, Nzarubara B, Maiteki-Sebuguzi C, Staedke SG, Seto E, Kamya MR, Rosenthal PJ, Dorsey G: Factors determining the heterogeneity of malaria incidence in children in Kampala, Uganda. J Infect Dis 2008, 198:393-400.

38. Kwiatkowski D: Cytokines and anti-disease immunity to malaria. Res Immunol 1991, 142:707-712.

39. Ofosu-Okyere A, Mackinnon MJ, Sowa MP, Koram KA, Nkrumah F, Osei YD, Hill WG, Wilson MD, Arnot DE: Novel Plasmodium falciparum clones and rising clone multiplicities are associated with the increase in malaria morbidity in Ghanaian children during the transition into the high transmission season. Parasitology 2001, 123:113-23.

40. Roper C, Richardson W, Elhassan IM, Giha H, Hviid L, Satti GM, Theander TG, Arnot DE: Seasonal changes in the Plasmodium falciparum population in individuals and their relationship to clinical malaria: a longitudinal study in a Sudanese village. Parasitology 1998, 116:501-510.

41. Cortés A, Mellombo M, Benet A, Lorry K, Rare L, Reeder JC: Plasmodium falciparum: distribution of msp2 genotypes among symptomatic and asymptomatic individuals from the Wosera region of Papua New Guinea. Exp Parasitol 2004, 106:22-29.

42. Magesa SM, Mdira KY, Babiker HA, Alifrangis M, Färnert A, Simonsen PE, Bygbjerg IC, Walliker D, Jakobsen PH: Diversity of Plasmodium falciparum clones infecting children living in a holoendemic area in north-eastern Tanzania. Acta Trop 2002, 84:83-92.

43. Bendixen M, Msangeni HA, Pedersen BV, Shayo D, Bødker R: Diversity of Plasmodium falciparum populations and complexity of infections in relation to transmission intensity and host age: a study from the Usambara Mountains, Tanzania. Trans R Soc Trop Med Hyg 2001, 95:143-148.

44. Vafa M, Troye-Blomberg M, Anchang J, Garcia A, Migot-Nabias F: Multiplicity of Plasmodium falciparum infection in asymptomatic children in Senegal: relation to transmission, age and erythrocyte variants. Malar J 2008, 7:17.

45. Akhwale W, Barnes K, Bjorkman A, Doumbo O, Makumbi I, McCarthy A, Omotade $\mathrm{O}$, White $\mathrm{NJ}$ : Intermittent preventive antimalarial treatment in infancy. Lancet 2008, 372:1383-1384.

46. Vinetz JM: Intermittent preventive treatment for malaria in sub-saharan African: a halfway technology or a critical intervention? Am J Trop Med Hyg 2010, 82:755-756.

47. Marks F, von Kalckreuth V, Kobbe R, Adjei S, Adjei O, Horstmann RD, Meyer CG, May J: Parasitological rebound effect and emergence of pyrimethamine resistance in Plasmodium falciparum after single-dose sulfadoxine-pyrimethamine. J Infect Dis 2005, 192:1962-1965.

doi:10.1186/1475-2875-9-244

Cite this article as: Buchholz et al:: Multiplicity of Plasmodium falciparum infection following intermittent preventive treatment in infants. Malaria Journal 2010 9:244.

\section{Submit your next manuscript to BioMed Central and take full advantage of:}

- Convenient online submission

- Thorough peer review

- No space constraints or color figure charges

- Immediate publication on acceptance

- Inclusion in PubMed, CAS, Scopus and Google Scholar

- Research which is freely available for redistribution
C Biomed Central 